\title{
Associations between occupational therapy students' academic performance and their study approaches and perceptions of the learning environment
}

T. Bonsaksen ${ }^{1,2,3^{*}}$ (D, T. A. Magne ${ }^{4}$, L. Stigen ${ }^{5}$, A. Gramstad ${ }^{6,7}$, L. Åsli , G. Mørk², S. G. Johnson ${ }^{8}$ and T. Carstensen ${ }^{4}$

\begin{abstract}
Background: Relationships between students' academic performance and their employed study approaches have been studied extensively. However, research using study approaches and learning environment factors as concurrent predictors of academic performance is sparse. There is a need to disentangle the potentially interrelated influences of individual and contextual factors on students' academic performance.

Objective: This study aimed to increase the understanding of the associations between occupational therapy students' academic performance, and their approaches to studying, perceptions of the learning environment, and sociodemographic characteristics.

Method: A cross-sectional study was designed, and 174 first-year students completed the Approaches and Study Skills Inventory for Students and the Course Experience Questionnaire, in addition to background information. Data on grades were collected from the data registries of each education institution, and associations were analyzed by multiple linear regression.

Results: None of the learning environment scales were associated with grades. Adjusting for all variables, better exam results were associated with being female $(\beta=0.22, p<0.01)$ and having higher scores on strategic approach $(\beta=0.31, p<0.001)$ and lower scores on surface approach $(\beta=-0.20, p<0.01)$.

Conclusion: The study suggests that students with a desire for obtaining good grades ought to use strategic study behaviors and avoid using surface approach behaviors. While it is important to ensure good quality of the learning environment for a variety of reasons, the learning environment did not contribute significantly to explain the students' academic performance.
\end{abstract}

Keywords: Academic performance, Approaches to studying, Grade point average, Higher education, Learning environment, Occupational therapy

\footnotetext{
* Correspondence: tore.bonsaksen@inn.no

${ }^{1}$ Department of Health and Nursing Sciences, Faculty of Social and Health

Sciences, Inland Norway University of Applied Science, Elverum, Norway

${ }^{2}$ Faculty of Health Studies, VID Specialized University, Sandnes, Norway

Full list of author information is available at the end of the article
}

(c) The Author(s). 2021 Open Access This article is licensed under a Creative Commons Attribution 4.0 International License, which permits use, sharing, adaptation, distribution and reproduction in any medium or format, as long as you give appropriate credit to the original author(s) and the source, provide a link to the Creative Commons licence, and indicate if changes were made. The images or other third party material in this article are included in the article's Creative Commons licence, unless indicated otherwise in a credit line to the material. If material is not included in the article's Creative Commons licence and your intended use is not permitted by statutory regulation or exceeds the permitted use, you will need to obtain permission directly from the copyright holder. To view a copy of this licence, visit http://creativecommons.org/licenses/by/4.0/ The Creative Commons Public Domain Dedication waiver (http://creativecommons.org/publicdomain/zero/1.0/) applies to the data made available in this article, unless otherwise stated in a credit line to the data. 


\section{Introduction}

Exams are summative assessments traditionally used to evaluate students' academic performance, and exam grades purport to measure students' learning outcomes. Previous research has described factors influencing academic performance as relating to two different sources. One focuses on the student's individual characteristics, of which some are fixed (such as gender) and others are changeable (such as motivation and study behaviors). The second focuses primarily on factors comprising the learning environment, for example the classroom climate and relationships among students [1-3]. In this article, study behaviors and learning environment factors are examined together as possible covariates to first-year occupational therapy students' academic performance.

In relation to individual characteristics, Bonsaksen and co-workers [4] described a range of socioeconomic factors characterizing Norwegian occupational therapy students. Some sociodemographic factors - in particular higher age and female gender - have been found to contribute to determine their academic performance $[5,6]$. In recent studies of occupational therapy students, having the current study program listed as the prioritized line of education at the time of enrolment has been shown to be associated with study behaviors [7, 8]. Moreover, having prior experience from higher education and spending more time on independent self-study has been shown to be associated with study behaviors [8, 9] and academic achievements [5, 6]. Thus, several individual factors appear to be relevant for an understanding of students' study behaviors and exam grades. However, the evidence concerned with sociodemographic covariates to academic performance across fields of study is inconsistent, as shown in a comprehensive review and meta-analysis covering a range of disciplines and professional courses [2]. Moreover, sociodemographic characteristics such as age and gender do not change like behaviors and environments can. Thus, a stronger focus on contextual factors and what can be done to influence them in ways that support students' learning, is recommended [10].

Other individual factors associated with academic performance, yet more amenable to change over time, are the students' approaches to studying. These have been named the deep, strategic, and surface approaches to studying and are well established across a range of settings and academic fields [11-14]. The deep approach is described as studying with the purpose of finding meaning in the topic in question and increasing one's understanding of it. The strategic approach is oriented towards organized studying, and studying is viewed as instrumental to obtaining high grades. The third approach, the surface approach, describes studying with little reflection, yet with the aim of passing exams while making little true effort [15]. Students often use a combination of attitudes and behaviors related to each of the three approaches; thus, they are not mutually exclusive [16]. Several studies have found study approaches to be significantly associated with academic outcomes. For example, Ward's studies $[17,18]$ demonstrated that medical students with who were more inclined to use deep and strategic study approaches obtained better grades, compared to students who were more inclined to use the surface approach. Approaches to studying have also been used to predict occupational therapy students' exam grades [6]. While five of the study approach subscales were significantly associated with the students' exam grades, not all associations were as predicted from theory [13, 19]. Moreover, associations between study approaches and academic performance have been found to vary between countries and cultures [20].

The learning environment generally refers to the educational approaches, cultural contexts and physical settings in which teaching and learning takes place. The perceived quality of the learning environment has been shown to have a direct impact on students' learning and exam results [21-24], as well as students' satisfaction with the course or study program [23, 25] and students' personal well-being [26]. However, the evidence for relationships between the learning environment and study performance is mixed. For example, direct associations between learning environment variables and academic grades were non-existing in a Norwegian study of higher education students [1]. On the other hand, studies from various disciplines, including occupational therapy, have consistently demonstrated associations between learning environment factors and students' approaches to studying [8, 27-31]. For instance, Richardson [32] studied 580 occupational therapy students in seven Danish universities and found that "students' perceptions of the quality of their courses are in broad terms also positively related to the adoption of desirable approaches and negatively related to the adoption of undesirable approaches" ( $p$. 200). These studies suggest that aspects of the learning environment influence study behaviors and may, in turn, influence academic performance. Moreover, studies have suggested that forms of teaching that modify the learning environment (e.g., group work, problem-based learning, case-study methods) seem to increase deep approach study behaviors [33-35].

In view of the available research evidence, much research effort has been invested in examining associations between study behaviors and measures of academic performance in higher education students. Several studies have also been able to demonstrate associations between the quality of the learning environment and students' academic performance, but such studies have not yet been conducted with students in occupational therapy. 
Learning environment factors have been shown to be associated with occupational therapy students' satisfaction with the education program [25] and their approaches to studying $[8,35]$, and a possible indirect influence from the learning environment on students' academic performance has been proposed. However, there is a need to disentangle the potentially interrelated influences of individual and contextual factors on occupational therapy students' academic performance. By using learning environment factors and approaches to studying as concurrent predictors of occupational therapy students' academic achievements, this study adds a unique contribution to the health sciences literature.

\section{Study aim}

The aim of the current study was to increase the understanding of the associations between occupational therapy students' academic performance, and their approaches to studying and perceptions of the learning environment. The research question for the study was: What is the nature of the associations between occupational therapy students' exam grades, and their approaches to studying, perceptions of the learning environment, and sociodemographic characteristics?

\section{Methods}

\section{Design and study context}

The study is part of a larger and longitudinal study of occupational therapy students' academic performance, in context of their perceptions of the learning environment and approaches to studying. In the current study, crosssectional data from students enrolled in the first year of the study program were used.

\section{Participants and recruitment}

First year occupational therapy students at six higher education institutions in Norway were approached for possible inclusion in the study. They were given information about the study in a classroom session and, after providing informed consent to participate, they were asked to complete the questionnaire in session or at a time and place of their own convenience. The data were collected between December 2017 and February 2018.

\section{Measurement}

\section{Sociodemographic variables}

Age (in years) and time spent on independent studying (average hours during a typical week) were registered as continuous variables. Gender (male/female), having prior experience from higher education (yes/no) and having occupational therapy as the highest prioritized line of education at the time of enrolment (yes/no) were registered as categorical variables.

\section{The learning environment}

In this study, the Course Experience Questionnaire (CEQ) was used to measure aspects of the learning environment. In its original version, the CEQ consists of 30 items distributed onto five scales: clear goals and standards, emphasis on independence, good teaching, appropriate workload, and appropriate assessment [36]. In addition to the 30 items, one item assesses the students' general satisfaction with the course. The validated Norwegian translation of the CEQ [37] was used in the present study. The scales indicate that the respondent perceives the course to have (1) clearly established and disseminated goals; (2) high levels of student autonomy and independence; (3) teaching that engages and involves the students; (4) an appropriate workload; and (5) assessment forms that promote and support learning. In view of the preliminary internal consistency results, the 'appropriate assessment' scale (Cronbach's $\alpha=0.45$ ) was removed from the subsequent analyses [38].

\section{Approaches to studying}

Study approaches were measured with the Approaches and Study Skills Inventory for Students [ASSIST; 19], and the students used a previously validated Norwegian translation of the instrument [39]. The ASSIST consists of 52 statements to which the respondent is asked to rate his or her level of agreement $(1=$ disagree, $2=$ disagree somewhat, $3=$ unsure, $4=$ agree somewhat, $5=$ agree). The instrument has a three-factor structure, recently replicated in a cross-cultural study of undergraduate occupational therapy students [40]. The items are organized accordingly into three main scales (the deep, strategic, and surface approaches to studying). Scale scores are calculated by adding the scores on the relevant items.

\section{Exam grades}

The students' average exam grade scores were based on the qualitative descriptors related to the students' exam grades [41]: fail $=1$, sufficient $=2$, satisfactory $=3$, good $=$ 4 , very $\operatorname{good}=5$, and excellent $=6$. As the exam grade measure, we used the students' grade point average (GPA) by the time the data was collected.

\section{Data analysis}

The sample was described with means and standard deviations on continuous variables, whereas frequencies and percentages are used on categorical variables. Men and women were compared statistically by Chi-square tests (categorical variables) and independent $t$-tests (continuous variables), and Cohen's $d$ was used as effect size [42]. Generally, $d$ ranging $0.20-0.49$ are considered small effect sizes, whereas $d$ ranging $0.50-0.79$ and 0.80 or 
above are considered medium and large effect sizes, respectively.

To assess the strength of associations between the independent variables and the students' GPA, a hierarchical linear regression analysis was performed using GPA as outcome variable. In Block 1, representing the background variables, age, gender, educational priority, prior higher education, and time spent on independent study were included as independent variables. In Block 2, representing the perceived learning environment, clear goals and standards, student autonomy, good teaching, and appropriate workload were included. In Block 3, representing the study approaches, the deep approach scale, strategic approach scale, and surface approach scale were included as independent variables. The strength of associations was assessed with the standardized $\beta$ coefficient. The regression models were also used to assess the outcome variance proportions accounted for by each of the models and by all variables together. All analyses were performed with SPSS for Windows, version 26 [43], and results were considered statistically significant if $p<0.05$.

\section{Research ethics}

The Data Protection Official at the Norwegian Center for Research Data approved the study on October 12, 2017 (project no. 55,875). The participants provided informed consent prior to the commencement of the study and were assured that their information would be treated in confidence.

\section{Results}

\section{Participants, response rate, and exam grades}

A total of 305 students were eligible participants, and of these 187 students (response rate $61.3 \%$ ) participated. For each of the institutions, the response rates were 24/ $76=31.6 \%$ in Oslo, $56 / 77=72.7 \%$ in Trondheim, $19 /$ $39=48.7 \%$ in Gjøvik, $31 / 47=66.0 \%$ in Sandnes, $24 /$ $24=100.0 \%$ in Troms $\varnothing$, and $33 / 45=73.3 \%$ in Bergen. Thirteen students had missing values on one or more of the employed variables and were consequently removed, rendering a sample of 174 students for the analysis.

The demographic characteristics and average exam grades of the study participants are displayed in Table 1. The sample was composed predominantly by female students $(81 \%)$. The mean age of the participants was 22.7 years $(S D=4.3$ years), where the male subset had a higher mean age than the female $(p<0.01)$. Compared to the female students, a higher proportion of the male students had prior experience from higher education before enrolment in the occupational therapy program $(p<0.05)$. The female students had obtained significantly better exam grades, compared to the male students $(p<$ $0.001)$.

\section{Learning environment and study approaches}

In the current study, internal consistency measures (Cronbach's $\alpha$ ) for the learning environment scales were 0.73 (clear goals and standards), 0.63 (emphasis on independence), 0.70 (good teaching), 0.69 (appropriate workload). Cronbach's $\alpha$ for the study approach scales were 0.71 (deep approach), 0.84 (strategic approach), and 0.76 (surface approach).

The mean ASSIST and CEQ scale scores for the sample are reported in Table 2. There were no significant gender differences related to the learning environment scales. Compared to their male counterparts, the female students showed significantly higher scores on the strategic approach scale $(p<0.05)$.

\section{Factors associated with exam grades}

The results from the regression analysis are displayed in Table 3. Adjusting for all variables in the final model, being female was associated with obtaining better exam results $(\beta=0.22, p<0.01)$. None of the learning environment scales were associated with the outcome. Among the study approach scales, better exam grades were associated with higher scores on strategic approach $(\beta=0.31$, $p<0.001)$, and lower scores on surface approach $(\beta=$ $-0.20, p<0.01$ ). The full model explained $27.5 \%$ of the variance in exam grades, with the sociodemographic

Table 1 Sociodemographic characteristics and average exam grades of the study participants

\begin{tabular}{|c|c|c|c|c|c|}
\hline \multirow[t]{2}{*}{ Variables } & $\begin{array}{l}\text { All } \\
n=174\end{array}$ & $\begin{array}{l}\text { Men } \\
n=33\end{array}$ & $\begin{array}{l}\text { Women } \\
n=141\end{array}$ & $p$ & \multirow[t]{2}{*}{$d$} \\
\hline & $M(S D)$ & $M(S D)$ & $M(S D)$ & & \\
\hline Age & $22.7(4.3)$ & $24.6(5.7)$ & $22.3(3.8)$ & $<0.01$ & 0.47 \\
\hline Time spent on self-study & $9.1(6.3)$ & $10.0(8.1)$ & $8.9(5.9)$ & 0.38 & 0.16 \\
\hline \multirow[t]{2}{*}{ Average exam grade } & $3.9(1.1)$ & $3.3(1.2)$ & $4.0(1.0)$ & $<0.001$ & -0.63 \\
\hline & $n(\%)$ & $n(\%)$ & $n(\%)$ & & \\
\hline Had OT as priority education & $106(60.9)$ & $20(60.6)$ & $86(61.0)$ & 0.97 & \\
\hline Had prior higher education & $73(42.0)$ & $19(57.6)$ & $54(38.3)$ & $<0.05$ & \\
\hline
\end{tabular}

Note. OT occupational therapy. Time spent on self-study is average number of hours spent during a typical week 
Table 2 The participants' approaches to studying and perceptions of the learning environment

\begin{tabular}{|c|c|c|c|c|c|}
\hline Variables & $\begin{array}{l}\text { All } \\
n=174\end{array}$ & $\begin{array}{l}\text { Men } \\
n=33\end{array}$ & $\begin{array}{l}\text { Women } \\
n=141\end{array}$ & $p$ & $d$ \\
\hline Study approach scales & $M(S D)$ & $M(S D)$ & $M(S D)$ & & \\
\hline Deep approach score & $56.5(8.7)$ & $58.5(11.7)$ & $56.1(7.8)$ & 0.16 & 0.24 \\
\hline Strategic approach score & $72.2(10.3)$ & $68.5(9.2)$ & $73.0(10.4)$ & $<0.05$ & -0.46 \\
\hline Surface approach score & $47.5(9.2)$ & $45.9(10.0)$ & $47.8(9.0)$ & 0.28 & -0.20 \\
\hline \multicolumn{6}{|l|}{ The learning environment } \\
\hline Clear goals and standards & $16.6(3.9)$ & $16.7(3.9)$ & $16.5(3.9)$ & 0.84 & 0.05 \\
\hline Student autonomy & $18.6(4.0)$ & $18.2(4.4)$ & $18.7(3.9)$ & 0.58 & -0.12 \\
\hline Good teaching & $27.3(6.1)$ & $26.2(5.3)$ & $27.6(6.3)$ & 0.27 & -0.24 \\
\hline Appropriate workload & $15.2(3.7)$ & $15.4(3.5)$ & $15.1(3.7)$ & 0.61 & 0.08 \\
\hline
\end{tabular}

variables and the study approach scales accounting for similar proportions $(11.5 \%$ and $11.2 \%$, respectively).

\section{Discussion}

This study investigated how exam grades in a sample of Norwegian occupational therapy students were associated with the students' background variables, their

Table 3 Factors associated with the participants' grade point average $(n=174)$

\begin{tabular}{|c|c|c|}
\hline \multirow{2}{*}{$\frac{\text { Independent variables }}{\text { 1) Demographics }}$} & \multicolumn{2}{|c|}{ Average exam grade } \\
\hline & Std. $\beta$ & $P$ \\
\hline Age & 0.05 & 0.52 \\
\hline Gender & 0.22 & $<0.01$ \\
\hline Educational priority & 0.11 & 0.11 \\
\hline Prior higher education & 0.00 & 0.99 \\
\hline Time spent on self-study & -0.10 & 0.20 \\
\hline Explained variance & $11.5 \%$ & $<0.01$ \\
\hline \multicolumn{3}{|l|}{ 2) The learning environment } \\
\hline Clear goals and standards & 0.02 & 0.83 \\
\hline Student autonomy & -0.10 & 0.25 \\
\hline Good teaching & 0.12 & 0.16 \\
\hline Appropriate workload & -0.03 & 0.69 \\
\hline$R^{2}$ change & $4.7 \%$ & 0.06 \\
\hline Explained variance & $16.3 \%$ & $<0.001$ \\
\hline \multicolumn{3}{|l|}{ 3) Study approach scales } \\
\hline Deep approach score & -0.06 & 0.44 \\
\hline Strategic approach score & 0.31 & $<0.001$ \\
\hline Surface approach score & -0.20 & $<0.01$ \\
\hline$R^{2}$ change & $11.2 \%$ & $<0.001$ \\
\hline Explained variance & $27.5 \%$ & $<0.001$ \\
\hline
\end{tabular}

Note. Table content is standardized $\beta$ weights, indicating the strength of each variable's relationship with average exam grade controlling for all variables in the model, and $p$-values associated with these relationships. Variable coding: male $=0$, female $=1$; occupational therapy was first priority $=1$, occupational therapy was not first priority $=0$, prior higher education $=1$, no prior higher education $=0$. On all other variables, higher scores indicate higher levels perceptions of the learning environment and their approaches to studying. None of the learning environment scales were significantly associated with the students' grades. Adjusting for all variables, we found that better exam grades were associated with being female, and with higher scores on the strategic scale and lower scores on the surface scale.

In view of previous research in other fields and disciplines, we had expected to find associations between some of the learning environment variables and the students' academic outcomes. For example, in a study using the CEQ, higher perceived workload was previously found to be directly associated with poorer study performance [27]. Another study, in which a different learning environment measure was used, found higher teacher support for student autonomy to be associated with better performance [23]. In our study, despite significant differences in learning environment perceptions being detected across study sites [44], no associations between learning environment factors and study performance were found. These findings imply that variations in academic performance were essentially unrelated to how the students perceived the learning environment. Despite dissimilarities with regards to field of study and measurement methods, these results appear to echo a recent Norwegian study, in which no direct associations between learning environment variables and the students' academic grades were found [1]. Thus, there is mixed evidence related to the role of the learning environment for students' academic performance. However, the results of this study should not be interpreted as evidence of the learning environment being irrelevant. In fact, studies have demonstrated associations between learning environment factors and students' use of study approaches $[8,27-30,35]$, suggesting that learning environment factors may influence academic performance indirectly by influencing study behaviors. In addition, their relationship to students' satisfaction with courses and study programs [23, 25] and students' well-being 
[26] strongly suggest that they are important for several good reasons.

The associations between exam grades and the scores on the strategic and surface study approach scales are in line with previous studies in fields such as psychology [12], medicine [17, 18, 44-46], and health science education more in general [48]. The results also mirror the study of associations between study approaches and exam grades in a cross-cultural sample of occupational therapy students [6]. Thus, the study results corroborate the notion that strategic and surface approaches to studying are related to students' academic performance and supports the notion that these associations are relatively similar across contexts and fields of study. While students with predominant strategic study behaviors tend to perform better academically, those with predominant surface study behaviors perform more poorly.

However, no association was found between the students' academic performance and their scores on the deep approach scale. While existing theory and research have suggested deep study behaviors and students' exam grades to be intrinsically linked (e.g., [2, 19, 47, 49]), other researchers have questioned this idea [50, 51]. Moreover, some researchers have expressed a view that the deep-surface dichotomy is overly simplistic, suggesting that study behaviors appear in a broader context (e.g., the nature of the knowledge to be acquired) - thus, the deep approach is not universally preferred [52]. This may have particular relevance for education programs that emphasize practice and skills training, such as the Norwegian occupational therapy programs. Possibly, although extensively used in health and medical education programs across the world [17, 18, 45, 47, 48, 53-56], the content of the ASSIST scale items may fit better when applied in academic contexts focused on critical thinking concerned with the evidence and rationale for different forms of practice, compared to contexts in which students work on mastering practical skills. For example, a student whose study approach leans largely towards the deep approach in academic contexts may respond differently to items related to reading, linking ideas and comprehensive understanding, while focused on improving practical skills. Although the questionnaires were completed while undergoing campus-based study modules, the study programs' orientation towards practice and practical skills may have influenced scores on the deep approach scale and how they related to students' exam grades.

The results of the current study provide support for Ward's [18] interpretation, suggesting that decreasing surface-type study behaviors among students may be more beneficial for their academic performance than increasing students' deep-type behaviors. In addition, clusters of study approaches - e.g., having high scores on strategic study behaviors combined with low scores on surface behaviors - may be particularly important in relation to students' academic performance.

It should be noted that exam grades are not perfect expressions of students' academic ability. Grades express academic performance within a given assessment context, and according to constructive alignment theory [57], both the frequency and type of assessment are likely to influence the students' ways of managing the course. Thus, the lack of association between grades and the deep approach scale score may reflect assessment forms used in the occupational therapy programs that do not favor deep learning.

Female students received better exam grades than their male counterparts. Occupational therapy is a profession with a large over-representation of women, among practitioners as well as among students, educators and researchers $[4,58]$, and it has been suggested that the female dominance in the profession might make it easier for female students to succeed within the established culture [59]. The study points towards a need for conducting more research on the male minority of occupational therapy students, addressing their perceived needs in the study situation and their views on what can assist their success as students and future occupational therapists.

\section{Study strengths and limitations}

A strength of the study is the use of data from all of the occupational therapy education programs in Norway, adding to the generalizability of the results. The total sample was sufficient in size for a multiple regression analysis with a relatively large number of independent variables. However, the response rates varied substantially between education programs, which may have biased the results with more weight given to education institutions with higher response rates. The crosssectional study design does not allow for causal interpretations of the results. Future studies may examine the extent to which approaches to studying can predict academic outcomes at subsequent assessments, and whether study approaches can mediate relationships between learning environment factors and subsequent academic outcomes. Moreover, research may further explore the situation for male students enrolled in occupational therapy study programs. Finally, given that a substantial outcome variance proportion is left unexplained by the tested regression model, we suggest that future studies include more relevant variables that can account for variance in grades among students. Such variables may include academic achievements prior to those obtained in the current study program, personality factors, and direct measures of study motivation. 


\section{Conclusions}

The students' perceptions of the learning environment were not significantly associated with the grades they obtained, whereas higher scores on the strategic approach scale and lower scores on the surface approach scale were significantly associated with better grades. Occupational therapy students with a desire for obtaining good grades are therefore advised to use strategic study behaviors and avoid using surface approach behaviors. In the development of courses and study programs, educators should strive to organize curricula, assignments and exams in ways that discourage students from relying on a surface approach to studying. They may also routinely assess study behaviors among their students and target students inclined to use the surface study approach for courses or support programs aimed at learning how to study successfully. In addition, organizing student mentoring groups, where successful advanced students share their views and experiences with more inexperienced students, may be useful for students who need support with their studies.

\section{Abbreviations}

ASSIST: Approaches and study skills inventory for students; CEQ: Course experience questionnaire; GPA: Grade point average; M: Mean; SD: Standard deviation

\section{Acknowledgements}

The authors would like to thank the students who volunteered to take part in this study. In addition, we thank Vår Mathisen (The Arctic University of Norway, Tromsø) and Kjersti Velde Helgøy (VID Specialized University, Sandnes), who contributed to the data collection for this study.

\section{Authors' contributions}

TB is the project manager and initiated the project. All authors contributed to the study design and data collection. TB and TC drafted the manuscript in collaboration. All authors read and made critical revisions to the manuscript and agreed to be responsible for the content of the final submitted version.

\section{Funding}

The study received no funding from any source.

\section{Availability of data and materials}

The datasets generated during and/or analyzed during the current study are not publicly available due to the still ongoing research process but are available from the corresponding author on reasonable request.

\section{Declarations}

\section{Ethics approval and consent to participate}

All protocols for collecting, storing and utilizing the data were approved by the Norwegian Center for Research Data (project no. 55875). All methods were carried out in accordance with relevant guidelines and regulations. All participants provided written informed consent to participate.

\section{Consent for publication}

Not applicable.

\section{Competing interests}

The authors declare that they have no competing interests.

\section{Author details}

${ }^{1}$ Department of Health and Nursing Sciences, Faculty of Social and Health Sciences, Inland Norway University of Applied Science, Elverum, Norway.

${ }^{2}$ Faculty of Health Studies, VID Specialized University, Sandnes, Norway.
${ }^{3}$ Department of Occupational Therapy, Prosthetics and Orthotics, Faculty of Health Sciences, Oslo Metropolitan University, Oslo, Norway. ${ }^{4}$ Department of Neuromedicine and Movement Science, Faculty of Medicine and Health Science, Norwegian University of Science and Technology, Trondheim, Norway. ${ }^{5}$ Department of Health Sciences, Faculty of Medicine and Health Science, Norwegian University of Science and Technology, Gjøvik, Norway. ${ }^{6}$ UiT The Arctic University of Norway, Troms $\varnothing$, Norway. ${ }^{7}$ Centre for care research, Tromsø, Norway. ${ }^{8}$ Department of Occupational Therapy, Faculty of health and function, Western Norway University of Applied Sciences, Bergen, Norway.

Received: 4 December 2020 Accepted: 11 September 2021

Published online: 18 September 2021

\section{References}

1. Vikstøl Olsen AK, Spieler K, Kovač VB. The role of individual processes and learning environment in the prediction of grades in a sample of Norwegian students. Cogent Educ. 2018:5:1.

2. Richardson M, Abraham C, Bond R. Psychological correlates of university students' academic performance: A systematic review and meta-analysis. Psychol Bull. 2012; 138:353-387.

3. Robbins SB, Lauver K, Le H, Davis D, Langley R, Carlstrom A. Do psychosocial and study skill factors predict college outcomes? A meta-analysis. Psychol Bull. 2004; 130:261-288.

4. Bonsaksen $T$, Kvarsnes $H$, Dahl M. Who wants to go to occupational therapy school? Characteristics of Norwegian occupational therapy students. Scand J Occup Ther. 2016; 23:297-303.

5. Bonsaksen T. Predictors of academic performance and education programme satisfaction in occupational therapy students. Br J Occup Ther. 2016; 79(6):361-367

6. Bonsaksen T, Brown T, Lim HB, Fong K. Approaches to studying predict academic performance in undergraduate occupational therapy students: a cross-cultural study. BMC Med Educ. 2017; 17:76.

7. Thørrisen MM, Mørk G, Åsli LA, Gramstad A, Stigen L, Magne TA, Carstensen T, Johnson SG, Brown T, Lim HB, Fong K, Bonsaksen T. Student characteristics associated with dominant approaches to studying comparing a national and an international sample (early online). Scand J Occup Ther. 2020

8. Mørk G, Magne TA, Carstensen T, Stigen L, Åsli LA, Gramstad A, Johnson SG, Bonsaksen T. Associations between learning environment variables and students' approaches to studying: a cross-sectional study. BMC Med Educ. 2020; 20:120.

9. Bonsaksen T, Sadeghi T, Thørrisen MM. Associations between self-esteem, general self-efficacy, and approaches to studying in occupational therapy students: A cross-sectional study. Occup Ther Mental Health. 2017; 33:326341.

10. Richardson JTE. Approaches to studying across the adult life span: Evidence from distance education. Learn Indiv Diff. 2013; 26:74-80.

11. Byrne M, Flood B, Willis P. Validation of the approaches and study skills inventory for students (ASSIST) using accounting students in USA and Ireland: A research note. Account Educ. 2004; 13:449-459.

12. Diseth $\AA$, Martinsen $\varnothing$. Approaches to learning, cognitive style, and motives as predictors of academic achievement. Educ Psychol. 2003: 23:195-207.

13. Entwistle N, Tait $H$, McCune V. Patterns of response to an approaches to studying inventory across contrasting groups and contexts. Eur J Psychol Educ; 2000; 15:33-48.

14. Kreber $C$. The relationship between students' course perception and their approaches to studying in undergraduate science courses: A Canadian experience. Higher Educ Res Devel. 2003; 22:57-75.

15. Entwistle N, McCune $V$. The conceptual bases of study strategy inventories. Educ Psychol Rev. 2004; 16:325-345.

16. Entwistle N. Research into student learning and university teaching. In: British Journal of Educational Psychology, Monograph Series II: Psychological Aspects of Education - Current Trends, No. 4. Edited by Entwistle N, Tomlinson P. Leicester, UK: British Psychological Society; 2007 $1-18$

17. Ward PJ. First year medical students' approaches to study and their outcomes in a gross anatomy course. Clin Anat. 2011; 24:120-127.

18. Ward PJ. Influence of study approaches on academic outcomes during preclinical medical education. Med Teach. 2011; 33:e651-e662. 
19. Tait H, Entwistle N, McCune V. ASSIST: A reconceptualisation of the Approaches to Studying Inventory. In: Improving student learning: Improving students as learners. Edited by Rust C. Oxford, UK: Oxford Center for Staff and Learning; 1998: 262-271.

20. Bonsaksen T, Brown T, Lim HB, Fong K, Småstuen MC. Associations between occupational therapy students' approaches to studying and their academic grade results: a cross-sectional and cross-cultural study. J Occup Ther Educ. 2020; 4:1-15.

21. Nouh T, Anil S, Alanazi A, Al-Shehri W, Alfaisal N, Alfaris B, Alamer E. Assessing correlation between students perception of the learning environment and their academic performance. J Pak Med Assoc. 2016; 66: 1616-1620.

22. Aluri VLN, Fraser BJ. Students' perceptions of mathematics classroom learning environments: measurement and associations with achievement. Learn Environ Res. 2019; 22:409-426.

23. Bonem EM, Fedesco HN, Zissimopoulos AN. What you do is less important than how you do it: the effects of learning environment on student outcomes. Learn Environ Res. 2020; 23:27-44.

24. Oluwatayo AA, Aderonmu PA, Aduwo EB. Architecture students' perceptions of their learning environment and their academic performance. Learn Environ Res. 2015: 18:129-142.

25. Thygesen H, Gramstad A, Åsli LA, Stigen L, Magne TA, Carstensen T, Bonsaksen T. Associations between learning environment variables and satisfaction with the education program among occupational therapy students. Irish J Occup Ther. 2020; 48:91-100.

26. Wasson LT, Cusmano A, Meli L, Louh I, Falzon L, Hampsey M, Young G, Shaffer J, Davidson KW. Association between learning environment interventions and medical student well-being: a systematic review. JAMA. 2016; 316:2237-2252.

27. Diseth $\AA$. Students' evaluation of teaching, approaches to learning, and academic achievement. Scand J Educ Res. 2007; 51:185-204.

28. Diseth $\AA$, Pallesen S, Brunborg GS, Larsen S. Academic achievement among first semester undergraduate psychology students: the role of course experience, effort, motives and learning strategies. Higher Educ. 2010; 59: 335-352.

29. Lizzio A, Wilson K, Simons R. University students' perceptions of the learning environment and academic outcomes: Implications for theory and practice. Stud Higher Educ. 2002; 27:27-52

30. Sun H, Richardson JTE. Students' perceptions of the academic environment and approaches to studying in British postgraduate business education. Assess Eval Higher Educ. 2016; 41:384-399.

31. Pires E, Daniel-Filho DA, de Nooijer J, Dolmans D. Collaborative learning: Elements encouraging and hindering deep approach to learning and use of elaboration strategies. Med Teach. 2020:1-9.

32. Richardson JTE. Perceived academic quality and approaches to studying in higher education: Evidence from Danish students of occupational therapy. Scand J Educ Res. 2010; 54:189-203.

33. Ballantine JA, Duff A, Larres PM. Accounting and business students' approaches to learning: A longitudinal study. J Account Educ. 2008; 26:188-201.

34. Hall M, Ramsay A, Raven J. Changing the learning environment to promote deep learning approaches in first-year accounting students. Account Educ. 2004; 13:489-505.

35. Sadlo G, Richardson JTE. Approaches to studying and perceptions of the academic environment in students following problem-based and subjectbased curricula. Higher Educ Res Develop. 2003; 22:253-274.

36. Ramsden P. A performance indicator of teaching quality in higher education: The Course Experience Questionnaire. Stud Higher Educ. 1991; 16:129-150.

37. Pettersen RC. Students' experience with and evaluation of teaching and the learning environmenet: Presentation of the Course Experience Questionnaire (CEQ) and validation of three Norwegian versions [in Norwegian: Studenters opplevelse og evaluering av undervisning og læringsmiljø: Presentasjon av Course Experience Questionnaire (CEQ) og validering av tre norske versjoner, Erfaringer med studiet (EMS)]. Halden, Norway: Østfold University College. Report no. 4; 2007.

38. Bonsaksen T, Gramstad A, Mørk G, Johnson SG. Perceptions of assessment in Norwegian occupational therapy students. J Occup Ther Educ. 2019; 3: Article 2.

39. Diseth $\AA$. Validation of Norwegian version of the Approaches and Study Skills Inventory for Students (ASSIST): Application of structural equation modelling. Scand J Educ Res. 2001; 45:381-394.
40. Bonsaksen T, Småstuen MC, Thørrisen MM, Fong K, Lim HB, Brown T. Factor analysis of the Approaches and Study Skills Inventory for Students in a cross-cultural undergraduate occupational therapy student sample. Austral Occup Ther J. 2019; 66:33-43.

41. The Norwegian Asociation og Higher Education Institutions. The grading system - general, qualitative descriptions. Accessed 4 June 2021 from https://www.uhr.no/_f/p1/i4bfb251a-5e7c-4e34-916b-85478c61a800/kara ktersystemet_generelle_kvalitative_beskrivelser.pdf

42. Cohen J. A power primer. Psychol Bull.1992; 112:155-159.

43. IBM Corporation: SPSS for Windows, version 26. Armonk, NY: IBM Corporation; 2019.

44. Thordardottir B, Stigen L, Magne TA, Johnson SG, Gramstad A, Gran AW, Åsl LA, Mørk G, Bonsaksen T. Student perceptions of the learning environment in Norwegian occupational therapy education programs (early online) Scand J Occup Ther. 2020

45. May W, Chung E-K, Elliot D, Fisher D. The relationship between medical students' learning approaches and performance on summative high-stakes clinical performance examination. Med Teach. 2012; 34:236-241.

46. Subasinghe SDLP, Wanniachchi DN. Approach to learning and the academic performance of a group of medical students - any correlation? Stud Med J. 2009; 3:5-10.

47. Mattick K, Dennis I, Bligh J. Approaches to learning and studying in medical students: validation of a revised inventory and its relation to student characteristics and performance. Med Educ. 2004; 38:535-543.

48. Salamonson Y, Weaver R, Chang S, Koch J, Bhathal R, Khoo C, Wilson I. Learning approaches as predictors of acacdemic performance in first year health and science students. Nurse Educ Today. 2013; 33:729-733.

49. Entwistle N. Student learning and academic understanding: a research perspective with implications for teaching. London: Elsevier; 2018.

50. Herrmann KJ, McCune V, Bager-Elsborg A. Approaches to learning as predictors of academic achievement: Results from a large scale, multi-level analysis. Högre Utbild. 2017; 7:29-42.

51. Campbell CM, Cabrera AF. Making the mark: Are grades and deep learning related? Res Higher Educ. 2014; 55:494-507.

52. Beattie V, Collins B, McInnes B. Deep and surface learning: a simple or simplistic dichotomy? Account Educ. 1997; 6:1-12.

53. Chonkar SP, Ha TC, Chu SSH, Ng AX, Lim MLS, Ee TX, Ng MJ, Tan KH. The predominant learning approaches of medical students. BMC Med Educ. 2018, 18:1.

54. Gramstad A, Åsli LA, Johnson SG, Magne TA, Carstensen T, Mørk G, Stigen L, Bonsaksen T. Approaches to studying: A cross-sectional comparison of occupational therapy students in six education programs in Norway. Open J Occup Ther. 2020, 8:1-9.

55. DaLomba E, Mansur S, Bonsaksen T, Greer MJ. Exploring graduate occupational and physical therapy students' approaches to studying, selfefficacy, and positive mental health. BMC Med Educ. 2021; 21:124.

56. Breen-Franklin A, Bonsaksen T. Associations between study approaches and exam grades among occupational therapy students in the United States (early online). Irish J Occup Ther. 2021.

57. Biggs J, Tang C. Teaching for quality learning at university. Berkshire: UK: Oxford University Press; 2011

58. Pollard N, Walsh S. Occupational therapy, gender and mental health: An inclusive perspective? Br J Occup Ther. 2000; 63:425-431.

59. Watson J. Progression routes and attainment in occupational therapy education: the impact of background characteristics. Br J Occup Ther. 2013; 76):520-527.

\section{Publisher's Note}

Springer Nature remains neutral with regard to jurisdictional claims in published maps and institutional affiliations. 